\title{
Necessidades formativas de condutores de visitantes em Parques Nacionais
}

\section{Educational needs of visitors' instructors in National Parks}

\author{
Marcial Cotes, William das Neves Salles, Alexandre Schiavetti, \\ Juarez Vieira do Nascimento
}

RESUMO: Conduzir visitantes em trilhas de longa duração em Parques Nacionais (PARNAs) envolve o saber se movimentar e, ao mesmo tempo, a percepção do ambiente natural. O ofício de educar deve estar intrínseco na profissão de condutor, seja na interpretação do bioma ou na necessidade formativa para lidar, informar, educar e proporcionar segurança aos visitantes, por meio de suas abordagens ou interpretações. Porém, pouco se conhece sobre o perfil e as necessidades formativas dos condutores dos PARNAs no Brasil. Assim, este estudo teve como objetivo identificar as necessidades formativas de 79 condutores de visitantes dos PARNAs do Caparaó (PNC) e Serra da Capivara (PNSC). As informações foram coletadas a partir de entrevista semiestruturada, cujo tema gerador contemplou as necessidades formativas apontadas pelos condutores. Os resultados revelam que os condutores investigados apresentam preferência por cursos de capacitação predominantemente práticos e que contemplem mais a realidade específica de cada PARNA investigado. Neste sentido, os profissionais apontam as necessidades de que os cursos possuam caráter prático e sejam ministrados no interior dos PARNAs, contemplando tanto os conhecimentos instrumentais necessários à atividade de condução quanto as características ecológicas específicas do parque, região, bioma e ecossistema em que as atividades ocorrem. Os cursos mais reivindicados pelos condutores investigados foram os de primeiros socorros, os de segundo idioma e os de características ecológicas do parque, da região, do bioma e do ecossistema.

PALAVRAS-CHAVE: Ecoturismo; Parques Nacionais; Condutor de Visitante; Necessidades Formativas. 


\section{ABSTRACT}

Driving visitors on long-distance trails in National Parks (PARNAs) involves knowing how to move and, at the same time, perceiving the natural environment. The job of educating must be intrinsic to the drivers' profession, either in the interpretation of the biome or in the formative need to deal with, inform, educate, and provide security to the visitors, through their approaches or interpretations. However, there is little information on the profile and training needs of PARNA instructors in Brazil. So, this study aimed to identify the training needs of 79 instructors of the PARNAs of Caparaó (PNC) and Serra da Capivara (PNSC). Information was collected from semi-structured interviews, whose generating theme contemplated the educational needs pointed out by the instructors themselves. Results show that the investigated instructors have a preference for predominantly practical training courses that more closely reflect the specific reality of each PARNAs investigated. In this sense, professionals point out the need for the courses to be practical and delivered within the PARNAs, taking into account both the instrumental knowledge required for the professional activity and the specific ecological characteristics of the park, region, biome, and ecosystem in which the activities take place. The most claimed courses by the investigated instructors were first aid, second language, and ecological features of the park, region, biome, and ecosystem.

KEYWORDS: Ecotourism; National Parks; Visitor Instructors; Formative Needs.

\section{Introdução}

A demanda pelas atividades de lazer como caminhadas, ciclismo, canoagem, acampamentos e alpinismo, em áreas de Mata Atlântica, caracteriza "a identidade afetiva dos brasileiros com essa floresta" (TONHASCA Jr., 2004, p. 67). Uma das opções de lazer na natureza no país são as Unidades de Conservação (UC) federais. No Brasil, existem 72 Parques Nacionais (PARNAs), localizados nos diversos biomas (23 na Mata Atlântica, 19 na Amazônia, 13 no Cerrado, nove em Ambiente Marinho, sete na Caatinga e um no Pantanal). Destes, em virtude de distintos aspectos que influenciam a visitação desde estrutura adequada, situação fundiária e a existência ou não de plano de manejo, apenas dois não estão abertos à visitação (ASCOM, 2016).

Os PARNAs brasileiros dispõem de características estruturais distintas, que abrangem desde unidades que possuem pontos atrativos que permitem agrupamento de um número maior de visitantes em um único local (com infraestrutura e serviços apropriados) até ambientes que possuem apenas trilhas e mirantes que não necessitam de infraestrutura elaborada, uma vez que os visitantes se dispersam (ASCOM, 2016). Dos 70 PARNAs que estão atualmente abertos à visitação, nove apresentam estruturas complexas, 13 pequenas estruturas e 48 estruturas limitadas que compreendem trilhas rústicas, isolamento, dificuldade de acesso e alguns com visitação mediante prévio agendamento com os gestores (ASCOM, 2016). 
A estrutura adequada para visitação depende, especialmente, do perfil do visitante em relação à oferta do PARNA, pois essa demanda pode exigir desde a uma simples trilha e camping rústico até infraestrutura mais complexa, composta por centro de visitantes, auditório, restaurante, pousada e transporte interno. Ribas e Hickenbick (2012), neste sentido, adotam outra perspectiva ao considerar a infraestrutura básica para visitação. As autoras entendem que a infraestrutura básica necessária compreende o próprio condutor de visitantes, profissional que deve ter capacidade de promover o ecodesenvolvimento do turismo a partir do oferecimento de vivências que satisfaçam o visitante e sensibilizem-no para a conservação do meio ambiente visitado, bem como da criação de relações baseadas em princípios como reverência, afabilidade e afetividade. Para que sua atuação seja bemsucedida, portanto, o condutor necessita levar em consideração os recursos interpretativos disponíveis na localidade - os quais, segundo Ham (1992), exigem a adoção de estratégias de comunicação que fortaleçam a relação entre o visitante e o ambiente visitado. Um dos recursos mais utilizados para esta finalidade, em áreas protegidas, são as trilhas (PAGANI et al., 1996).

Para conhecer uma UC federal, o visitante caminha por um percurso previamente traçado de trilhas, termo definido na literatura consultada como os caminhos abertos que possuem diferenças em relação às formas, funções, distância percorrida e distintos níveis de dificuldade (VASCONCELOS, 2006; LECHENER, 2006; HUGO, 1999; COTES et al., 2007; COTES; MIELKE, 2013). Embora alguns PARNAs permitam a entrada de visitantes sem a companhia do condutor, este profissional pode trazer segurança, informações sobre a história da unidade e dicas de educação ambiental, o que pode propiciar uma experiência hedonista e bem-sucedida para aqueles que buscam trilhas de longa duração em UC (RIBAS; HICKENBICK, 2012; PEREIRA; SILVA; SILVA-JUNIOR, 2015).

Ao considerar que as atividades de guia e de monitor de turismo não podem ser confundidas com a de condutor, o Ministério do Turismo estabeleceu, em 2014, a exigência de curso de capacitação específico para exercer a função de condutor de visitantes em UC federais, estaduais ou municipais. Neste sentido, o condutor deve ter domínio de "conhecimentos ecológicos vivenciais e específicos da localidade em que atua" (MT, 2014, p. 2) para obter o cadastro na UC e exercer a atribuição de conduzir visitantes em espaços naturais e/ou em áreas legalmente protegidos. Em 2016, por sua vez, o Instituto Chico Mendes de Conservação da Biodiversidade (ICMBio) publicou normativa com o objetivo de regularizar o serviço de condução em PARNAs, orientando os profissionais a cumprirem determinados critérios e normas de visitação das UC federais, além de especificar a qualificação mínima e os mecanismos de avaliação e capacitação periódica dos condutores autorizados (BRASIL, 2016). Apesar de ser uma norma que objetiva regular a condução, o curto prazo estabelecido para que a mesma seja cumprida pelos condutores cadastrados, de somente 12 meses após sua publicação, deverá afetar seu cumprimento com a qualidade desejada.

Atividades na natureza, especialmente trilhas em ambientes naturais, envolvem o saber se movimentar e, ao mesmo tempo, a percepção do 
ambiente natural, o que requer uma complexa relação que abarca os sentidos (visão, audição, tato, olfato, paladar), além de raciocínio rápido e astúcia. Esta integração é denominada por Ingold (2007) de união, durante o caminhar, do deslocamento com a percepção - e que, no decorrer do percurso, constrói uma linha por meio dos pontos observados. A percepção, de acordo com Ingold (2000), é a aliciação operacional e exploratória do ser humano por inteiro, onde o corpo e o pensamento são inseparáveis em um mundo rico de estruturas complexas.

Ao percorrer uma trilha conduzindo visitantes no interior de uma UC, os olhos permitem tecer uma imagem da paisagem visual, os ouvidos possibilitam estabelecer uma representação sonora, o nariz um panorama olfativo, a boca a experiência do paladar, e a pele a sensação tátil. Jarvis (2015) denomina esse conjunto de sensações de aprendizagem préconsciente, ou ainda de uma interação constante entre o sujeito e a realidade externa, que possibilita o aparecimento de uma experiência mais elaborada, da qual nem sempre o sujeito encontra-se consciente. Além do conhecimento e da experiência adquiridos serem implícitos no conhecimento tácito, este tirocínio ocorre ao longo da vida, por meio do acúmulo de vivências (JARVIS, 2012; 2015) que não são, necessariamente, objetos de um processo educacional formal (NELSON; CUSHION; POTRAC, 2006; TRUDEL; CULVER; RICHARD, 2016). Neste sentido, os PARNAs são áreas privilegiadas, onde essas percepções podem ser exercitadas.

Nessa perspectiva, Ribas e Hickenbick (2012, p. 147) defendem a importância do condutor de visitantes como um "profissional da área do turismo e auxiliador da sensibilização e conservação ambiental, capaz de conduzir visitantes em diversos atrativos (sítios) turísticos naturais de sua localidade de ação - protegidos ou não". Canto-Silva e Silva (2017, p. 383) indicam a importância do papel dos condutores de visitantes aos PARNAs e defende a pertinência de pesquisas que identifiquem "o perfil, as limitações e as necessidades desses profissionais, de modo a melhorar a qualidade de vida dos envolvidos e qualificar os serviços de visitação oferecidos nas UCs". Os condutores de visitantes em PARNAs, de fato, são profissionais que possuem uma visão prática da realidade e do potencial de cada unidade onde opera, e teoricamente são os sujeitos mais indicados para apontar as necessidades formativas que contemplem as demandas de condução de cada UC.

Segundo Jacobson (1992), há quatro motivos para se aprimorar a formação de condutores: reduzir os impactos na localidade alvo; fortalecer a relação do condutor com a localidade, por meio da compreensão de seu papel para a conservação; melhorar a qualidade da visita para o visitante e; proporcionar fonte de receita para as comunidades locais. Para Pereira, Silva e Silva-Junior (2015) uma formação profissional eficaz do profissional é o princípio para que as atividades turísticas desenvolvam seu potencial educativo e colaborem com a conservação da UC visitada, o que é confirmado por Canto-Silva e Silva (2017).

Outro aspecto ressaltado por Pereira, Silva e Silva-Junior (2015) se refere à possibilidade da atividade de conduzir visitantes gerar emprego e 
renda aos moradores que residem no interior ou no entorno do PARNA, possibilidade está também apontada por Ribas e Hickenbick (2012). Os achados de Ribas e Hickenbick (2012), Pereira, Silva e Silva-Junior (2015) e Canto-Silva e Silva (2017) estão em conformidade com a instrução normativa $n^{\circ}$ 2, do ICMBio, de 3 de maio do 2016, que dispõe sobre normas e procedimentos administrativos para autorização de uso à prestação do serviço de condução de visitantes em UC federais. No Artigo 9º, indica-se ser "desejável que os condutores de visitantes sejam moradores do interior ou do entorno das unidades, de acordo com cada categoria de manejo" (BRASIL, 2016, p. 115).

Considerando o exposto, este estudo teve como objetivo investigar as necessidades formativas apontadas por 79 condutores de visitantes que atuam em trilhas de longa duração (TLD) de dois PARNAs. Acredita-se que essa investigação trará contribuições para expandir as evidências empíricas sobre as necessidades formativas dos condutores de PARNAs, além de conter informações relevantes para os gestores das UC do Brasil, bem como para os mais de 70 PARNAs existentes no território nacional em diferentes biomas.

\section{Procedimentos metodológicos}

\section{Caracterização do estudo}

Este estudo caracteriza-se como descritivo, de natureza exploratória (GIL, 2008), com abordagem qualitativa dos dados (FLICK, 2009). As pesquisas descritivas procuram estudar o nível de atendimento para 0 público que utiliza um determinado serviço, seja ele público ou não. Além disso, procuram analisar as opiniões das pessoas ou grupos sociais (GIL, 2008). As pesquisas exploratórias, por sua vez, buscam desenvolver, elucidar e alterar concepções e ideias, por meio da elaboração de pressupostos que poderão incidir em estudos posteriores; e, normalmente, utilizam de entrevistas para levantamento de dados, além da revisão de literatura e análise documental (MINAYO, 1994; THOMAS; NELSON, 2002). Quando o tema apresenta incipiência de investigações, Minayo (1994) recomenda o emprego da pesquisa exploratória, pois os resultados finais procuram elucidar os problemas identificados. Neste contexto, as pesquisas descritivas, agregadas com as pesquisas exploratórias, são utilizadas para analisar situações de desempenho profissional na prática (GIL, 2008). A abordagem qualitativa foi adotada porque reconhece a complexidade e a subjetividade presente nos fenômenos sociais (os quais não podem ser adequadamente quantificados e reduzidos aos números), buscando interpretar a situação investigada a partir das perspectivas dos indivíduos investigados. Esta abordagem permite, portanto, a adoção de postura mais reflexiva do investigador no processo de construção da pesquisa (FLICK, 2009).

\section{Contextos de investigação}

A Figura 1 mostra as áreas onde foi realizada a investigação: os PARNAs Serra da Capivara (PNSC) e do Caparaó (PNC). O PNSC é 
localizado na Região Nordeste do Brasil, no sudeste do estado do Piauí (PI) com clima semiárido e vegetação característica da região, a Caatinga. $O$ Parque abrange áreas dos municípios de São Raimundo Nonato, Coronel José Dias, São João do Piauí e Canto do Buriti, entre as coordenadas $08^{\circ}$ $26^{\prime} 50^{\prime \prime}$ e $08^{\circ} 54^{\prime} 23^{\prime \prime}$ de latitude sul e $42^{\circ} 19^{\prime} 47^{\prime \prime}$ e $42^{\circ} 45^{\prime} 51^{\prime \prime}$ de longitude oeste (SMAPR, 1994). A temperatura média anual é de $28^{\circ} \mathrm{C}$, apresentando variações entre $12^{\circ} \mathrm{C}$ no mês de junho e $45^{\circ} \mathrm{C}$ em outubro e novembro, com o início da época das chuvas se estendendo até metade de abril (EMPERAIRE, 1984).

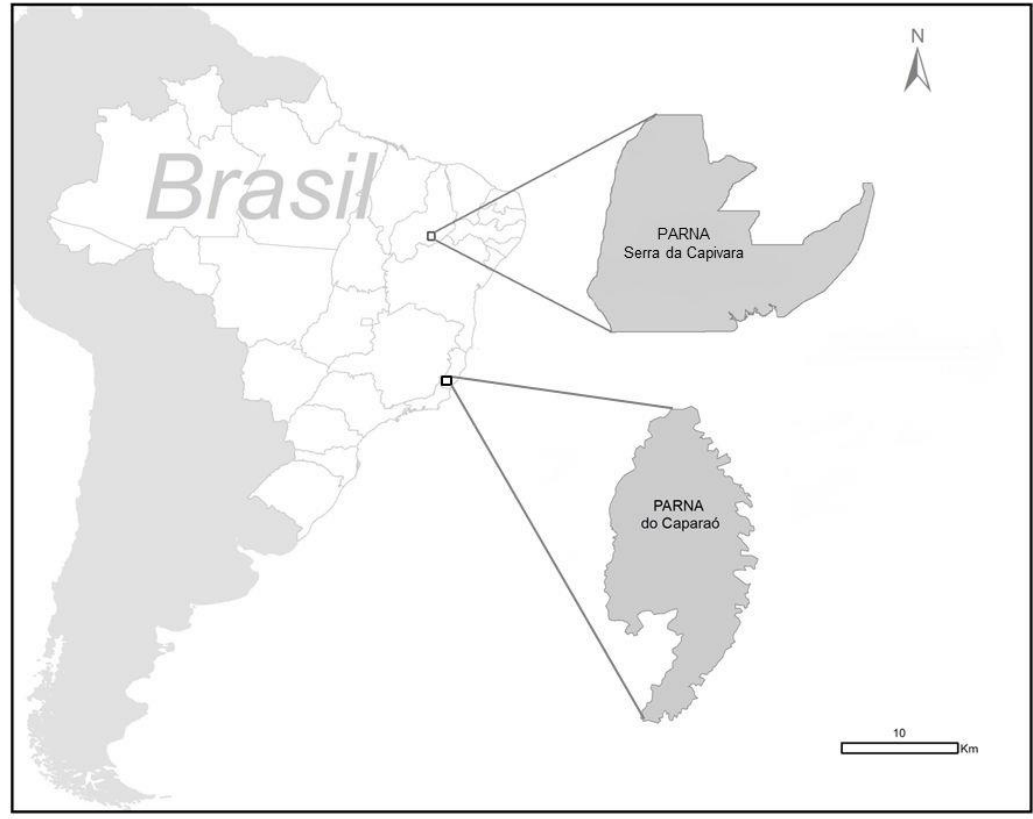

Figura 1. Mapa da localização dos PARNAs do

Caparaó (ES/MG) e Serra da Capivara (PI).

Figure 1. Location map of Caparaó (ES/MG) and Serra da Capivara (PI) PARNAs.

O PNC localiza-se na divisa dos estados Minas Gerais (Alto Caparaó, Alto Jequitibá, Divino, Espera Feliz, Manhuaçu, Presidente Soares e Lajinha) e Espírito Santo (Alegre, Divino de São Lourenço, Dores do Rio Preto, lúna, Irupi, Pedra Menina, Patrimônio da Penha e Ibitirama), no qual se concentra $70 \%$ da área (IBDF, 1981). O Parque está situado na terceira maior altitude do Brasil (Serra do Caparaó), entre os paralelos 2019 'S e 2037'S e os meridianos $41^{\circ} 43^{\circ} \mathrm{W}$ e $41^{\circ} 53^{\circ} \mathrm{W}$ (IBDF, 1981). O Caparaó tem relevo, em sua maioria, com altitude em torno de $2.000 \mathrm{~m}$, alcançando $2.892 \mathrm{~m}$ em seu cume (Pico da Bandeira). Áreas de menores altitudes estão nas partes do entorno, com cerca de $1.000 \mathrm{~m}$ (IBDF, 1981). O clima é caracterizado como tropical de altitude, cujas temperaturas variam entre $19^{\circ} \mathrm{C}$ e $2^{\circ} \mathrm{C}$, com a mínima atingindo até $-10^{\circ} \mathrm{C}$ no cume durante o inverno (IBAMA, 1995). A rede de drenagem do PNC é caracterizada por numerosos rios perenes, de pequeno e médio porte, sendo que a maior bacia é formada pelo rio Doce (IBDF, 1981). 


\section{Participantes do estudo}

Para a pesquisa representar, de fato, o perfil dos condutores de visitantes de ambos os PARNAs, foi feito um esforço amostral em ambas as UC federais para se abranger, no mínimo, $80 \%$ dos condutores de cada unidade. Os participantes do estudo, no PNSC, foram os condutores de visitantes credenciados pela portaria do ICMBio no 8, de 9 de abril de 2014 (ICMBio, 2014). No PNC, os condutores de visitantes eram credenciados no próprio Parque, mas sem portaria do ICMBio.

A seleção dos condutores do PNSC teve como critério a triagem com base na portaria $n^{\circ} 08$, do ICMBio (2014), de modo a selecionar condutores de visitantes credenciados que atuam com TLD. Dos 59 condutores que constam na portaria, 53 operam com TLD. Deste total, dois condutores não residem mais na região e um deixou de conduzir, pois passou em concurso público, totalizando 50 condutores. Do universo de 50 condutores de visitantes, foram entrevistados $80 \%(n=40)$, residentes nas cidades de São Raimundo Nonato e Coronel José Dias, no PI. Os demais não foram encontrados ou não quiseram participar da investigação.

Para o PNC, diferente do PNSC, por não haver obrigatoriedade de visitação acompanhada por um condutor, houve necessidade do auxílio da gestão da UC, que disponibilizou lista atualizada dos profissionais credenciados no parque, pois o PARNA encontra-se em processo de organização para atender à portaria de credenciamento do ICMBio (BRASIL, 2016). A lista totalizou 46 condutores de visitantes atuantes, sendo que sete estavam viajando, não foram encontrados ou não quiseram participar voluntariamente da pesquisa. Deste total, concederam entrevista semiestruturada $84,8 \%(n=39)$ dos condutores residentes nas cidades de Alto Caparaó em MG, Pedra Menina e Patrimônio da Penha, no ES. Neste sentido, 79 condutores foram investigados no presente estudo.

\section{Instrumentos de coleta de dados}

Os dados foram coletados por meio de entrevista semiestruturada, a qual foi conduzida junto aos condutores de visitantes dos dois PARNAS que concordaram em colaborar de forma voluntária com a pesquisa, após convite. O tema gerador da entrevista contemplou as necessidades formativas dos condutores. A opção pela entrevista semiestruturada está ligada à expectativa de que os pontos de vista dos sujeitos são mais facilmente expressos numa situação de entrevista semiestruturada aberta do que num questionário (FLICK, 2009). Para estimular a fala dos condutores, também foi utilizada uma guia com questionamentos e estímulos narrativos. A condução da entrevista pelo pesquisador teve como intuito o envolvimento do condutor consigo mesmo, induzindo lembranças para gerar informações. 


\section{Coleta, tratamento e análise dos dados}

A presente pesquisa foi encaminhada ao ICMBio e obteve a aprovação $\mathrm{n}$ 0 49700-1 (07 de julho de 2015). Após obter a autorização, a pesquisa foi submetida ao Comitê de Ética e Pesquisa (CEP) da Universidade Federal de Santa Catarina (UFSC) e teve sua autorização confirmada pelo protocolo CAAE 49119715.2.3001.5526, com ํㅜ 1.346.397. Após contatar os gestores das duas UC, convidaram-se os condutores a participar voluntariamente da pesquisa. Aqueles que concordaram, leram e assinaram o Termo de Consentimento Livre e Esclarecido (TCLE) e, posteriormente, realizaram a entrevista semiestruturada entre os dias 09 de novembro de 2015 e 31 de janeiro de 2016 .

As entrevistas ocorreram no interior e/ou no entorno do PARNA de atuação de cada condutor e foram realizadas individualmente, com o suporte de um gravador digital para a coleta das informações. Na sequência, as gravações foram transferidas para um computador e transcritas na íntegra, para posteriormente ser encaminhadas aos condutores para validação das declarações - momento em que podiam incluir ou suprimir informações. Adotou-se, no processo de validação comunicativa das entrevistas semiestruturadas, o método sugerido por Flick (2005), que indica a necessidade de um segundo contato com o entrevistado para que, em posse da entrevista transcrita, o próprio sujeito entrevistado possa conferir a autenticidade das informações colhidas, lendo o material e validando o seu conteúdo. Neste caso, a autenticidade da entrevista é dupla, pois "é obtida, após a entrevista, a concordância do entrevistado com os conteúdos de suas afirmações" (FLICK, 2005, p. 208).

A categorização dos dados qualitativos foi realizada por meio da técnica análise de conteúdo, de acordo com os procedimentos sugeridos por Bardin (2010): pré-análise, exploração do material e tratamento, inferência e interpretação dos resultados. O programa QSR NVivo 9.2, utilizado com 0 objetivo de trazer mais robustez à análise das informações qualitativas, foi empregado para organizar e analisar as transcrições das entrevistas. Este programa permite ao pesquisador classificar e organizar informações, ordenando-as em categorias e possibilitando a análise das similaridades e diferenças entre as informações.

A organização das informações das entrevistas foi feita de acordo com as unidades de significado que emergiram nas análises (a posteriori). As categorias foram definidas a partir da frequência de incidência das unidades de significado encontradas, para que fosse possível conhecer e revelar as necessidades formativas dos condutores. Neste sentido, duas grandes categorias resultaram deste processo: a) conhecimentos instrumentais; e b) características ecológicas do parque, região, bioma e ecossistema.

A representatividade das categorias (PATTON, 1990) foi confirmada a posteriori, a partir de um processo exaustivo de análise realizado em parceria com dois pesquisadores: um com vasta experiência em pesquisa qualitativa e em formação profissional na área de Educação Física, e outro 
com amplo conhecimento na área de Ciências Ambientais, com ênfase em gestão de áreas protegidas e análise de estratégias à conservação.

As informações quantitativas (dados de caracterização), por sua vez, foram inseridas em planilha do programa SPSS Statistics (versão 21.0) e analisadas a partir de recursos da estatística descritiva (frequência absoluta e relativa).

\section{Resultados e discussão}

\section{Perfil sociodemográfico, acadêmico e profissional dos condutores de visitantes}

O processo de levantamento de informações referentes às necessidades formativas dos condutores teve, como primeiro passo, a identificação das características sociodemográficas dos profissionais entrevistados. Os resultados apresentados na Tabela 1 indicam que, em ambos os PARNAs, há o predomínio da atuação de condutores do sexo masculino $(88,6 \%)$ em relação à participação feminina $(11,4 \%)$.

Tabela 1: Características sociodemográficas, acadêmicas e profissionais dos condutores.

Table 1: Sociodemographic, academic, and professional characteristics of the instructors.

\begin{tabular}{lllll}
\hline Variável & Categorias & $\begin{array}{l}\text { PNSC } \\
(\mathrm{n}=40)\end{array}$ & $\begin{array}{l}\text { PNC } \\
(\mathrm{n}=39)\end{array}$ & Total \\
\hline \multirow{2}{*}{ Sexo } & Masculino & 34 & 36 & $70(88,6 \%)$ \\
& Feminino & 6 & 3 & $9(11,4 \%)$ \\
Faixa etária & Até 30 anos & 4 & 14 & $18(22,8 \%)$ \\
& 31 a 40 anos & 26 & 11 & $37(46,8 \%)$ \\
Estado civil & 41 anos ou mais & 10 & 14 & $24(30,4 \%)$ \\
& Casado/União Estável & 23 & 21 & $44(55,7 \%)$ \\
Estado de residência & Solteiro/Viúvo/Divorciado & 17 & 18 & $35(44,3 \%)$ \\
& Piauí & 40 & 0 & $40(50,6 \%)$ \\
& Minas Gerais & 0 & 22 & $22(27,8 \%)$ \\
Nível de formação & Espírito Santo & 0 & 17 & $17(21,5 \%)$ \\
& Ensino Fundamental & 3 & 17 & $20(25,3 \%)$ \\
& Ensino Médio & 15 & 14 & $29(36,7 \%)$ \\
Experiência como condutor & Graduação & 12 & 7 & $19(24,1 \%)$ \\
Remuneração & Pós-Graduação 10 anos & 10 & 1 & $11(13,9 \%)$ \\
& 11 anos ou mais & 11 & 25 & $36(45,6 \%)$ \\
& Até 1 salário mínimo & 22 & 14 & $43(54,4 \%)$ \\
& Mais de 1 salário mínimo & 18 & 4 & $22(27,8 \%)$ \\
\hline
\end{tabular}

Fonte: Elaborada pelos autores. Source: Prepared by the authors. 
Embora a oferta de atividades de aventura na natureza esteja acessível às mulheres $e$, de fato, se perceba atualmente o crescimento da participação feminina nestas atividades (BRUHNS, 2003; SILVA, 2004), o mesmo não se pode afirmar para a atuação em atividades de aventura (PAIXÃO; TUCHER, 2010; PAIXÂO et al., 2011; PAIXÃO, 2012; PAIXÃO, 2013; PAIXÃO, 2015) e na condução de TLD nos PARNAs pesquisados.

A experiência prévia enquanto praticante, frequentemente, conduz à atuação futura como, neste caso, condutor de visitantes. Porém, a elevada participação do público feminino em tais atividades não tem implicado no aumento da participação de mulheres como condutoras de TLD nos PARNAs investigados. Acredita-se que essa vertente de prática se configura no Brasil como um fenômeno recente e, consequentemente, um campo de intervenção profissional eminentemente novo (PAIXÃO; TUCHER, 2010; PAIXÂO et al., 2011; PAIXÃO, 2012; PAIXÃO, 2013; PAIXÃO, 2015). Haja vista que as normas que regulam a profissão de condutor de visitantes são recentes (MT, 2014; BRASIL, 2016).

A faixa etária, de modo geral, não parece afetar o trabalho de condução no PNSC. Todavia, para alcançar o principal atrativo do PNC, ou seja, os 2.892 metros de altura do Pico da Bandeira, terceiro ponto mais alto do território brasileiro, uma faixa etária mais elevada pode compreender um fator limitante ao profissional que deseja chegar ao cume.

Com relação ao nível de formação dos condutores investigados, destaca-se que a maioria possui a Educação Básica completa ou incompleta $(62,0 \%)$, somente $38,0 \%$ estão cursando ou já concluíram algum curso de nível superior. Quando analisados separadamente os condutores de cada PARNA, observa-se que $22(55,0 \%)$ condutores do PNSC estão cursando ou já concluíram cursos de graduação ou pós-graduação, e 31 (79,5\%) condutores que atuam no PNC possuem apenas formação em nível básico.

Quanto à formação universitária dos 22 profissionais do PNSC, ressaltam-se os cursos de Geografia $(n=6)$, História $(n=5)$, Pedagogia $(n=3)$, Ciências Naturais $(n=2)$, Biologia $(n=2)$, Letras/Português $(n=1)$, Arqueologia $(n=1)$, Administração $(n=1)$ e Matemática $(n=1)$. Dos oito condutores do PNC, três realizaram o curso de Turismo, e os demais os cursos de Engenharia Civil, Desenho Industrial, Farmácia, Biologia e Educação Artística.

Dos entrevistados, 20 realizaram cursos de formação de professores, sendo que 18 condutores com este título atuam no PNSC e dois no PNC. Esse aspecto pode ser considerado positivo para os condutores com esta formação, pois a função apresenta características educacionais (PAIXÃO; TUCHER, 2010; PAIXÂO et al., 2011; PAIXÃO, 2012; RIBAS; HICKENBICK 2012, COLLINS; COLLINS, 2012; PAIXÃO, 2013; PEREIRA, SILVA; SILVAJUNIOR, 2015; PAIXÃO, 2015;). Paixão e Tucher (2010, p.3) sinalizam como particularidade do profissional atuante na prática das atividades de aventura na natureza, semelhante ao papel de condutor de visitantes, a necessidade de "sistematização das ações, estratégias e procedimentos adotados à luz da Pedagogia (nos domínios da didática)". 
Uma boa formação profissional é apontada por Canto-Silva e Silva (2017) e Pereira, Silva e Silva-Junior (2015) como imprescindível para que o trabalho de condução de visitantes apresente, também, cunho educativo. Neste sentido, Ribas e Hickenbick (2012, p. 148) defendem que o condutor de visitantes não tem somente papel de professor, mas deve atentar-se para a "conservação dos ecossistemas locais e para o bem-estar das populações envolvidas, não se esquecendo do bem-estar e da satisfação dos visitantes". Deste modo, consideram o condutor de visitantes protagonista para que 0 visitante alcance a satisfação em seu momento de lazer, motivo pelo qual este aspecto deve ser enfatizado nos programas ecoturísticos.

Irving (2002), ao discutir ética no turismo, se refere ao Ciclo da Intuição. Este deve ser focalizado "nos valores éticos, na ecologia, na natureza, no lazer, no tempo e no retorno aos valores essenciais" (IRVING, 2002 , p. 19), como propensão da sociedade na atualidade. No Ciclo da Intuição, o lazer valoriza os aspectos lúdicos do tempo livre, mas deve incorporar informações da cultura local e procedimentos educacionais. Complementarmente, Canto-Silva e Silva (2017, p. 369) definem o papel do condutor de visitantes como essencial pela sua importância à "sustentabilidade das UCs e para o desenvolvimento das comunidades locais", além de sugerirem que pesquisas sobre estes temas "são ainda incipientes, muitas vezes pontuais e específicas a uma ou outra área protegida (p. 369)", o que traz relevância aos dados de formação dos condutores apresentados no presente estudo e se alinha às normativas do ICMBio (BRASIL, 2016).

Ao considerar o tempo de experiência como condutor de visitantes, verificou-se que a maioria dos investigados exerce esta atividade há mais de 10 anos (54,4\%). A maior parte dos condutores do PNSC (72,5\%) possui 11 anos ou mais de experiência, enquanto a maioria dos condutores do PNC $(64,1 \%)$ exerce a atividade há 10 anos ou menos.

Para Jarvis (2015), ter mais de 10 anos de experiência é um fator favorável para qualquer profissional. $\mathrm{O}$ autor compreenderia esse processo de aprendizagem, ocorrido no decorrer do tempo de trabalho de condução de visitantes em PARNAs, como um conjunto de interações constantes entre o condutor e o ambiente externo. É importante salientar que estes conhecimentos tácitos, adquiridos durante anos de prática profissional, nem sempre são objeto de consciência desses indivíduos, motivo pelo qual se fala que são implícitos ou pré-conscientes (JARVIS, 2015).

Com base na teoria da aprendizagem de Jarvis (2012; 2013; 2015), pode-se indicar que o aprendizado de condução de visitantes ocorre ao longo da vida dos condutores, por meio da capitalização de experiências que não são, necessariamente, objetos de um processo de educação formal ou não-formal (NELSON; CUSHION; POTRAC, 2006; JARVIS, 2012; TRUDEL; CULVER; RICHARD, 2016), mas de sua própria prática profissional cotidiana no PARNA, a qual desencadeia inúmeras situações de aprendizagem informal que resultam na consolidação de saberes implícitos à atuação (SCHÖN, 2008). 
Os profissionais investigados possuem experiência considerável na condução de visitantes - principalmente os que atuam no PNSC, onde foi possível averiguar sistematização de cursos de capacitação de condutores desde 1993 (ICMBio, 2014). De fato, a especificidade dos diferentes ambientes naturais nos quais são praticadas as diversas atividades, seja de aventura ou educacional, exige do condutor uma vivência prática específica, possibilitando o domínio aprofundado das características do bioma e do local em que atua, bem como da atividade que desenvolve. Ressalta-se que o PNC e o PNSC possuem características distintas no que diz respeito às atividades desenvolvidas, ao tipo de fauna e flora, à estrutura e ao tipo do solo das trilhas, aos atributos culturais, à formatação de trilhas interpretativas, ao conteúdo educacional, ao clima e à geografia da região em que estão localizados.

De modo geral, os condutores investigados recebem até um salário mínimo por mês (72,2\%). Apenas $18(45,0 \%)$ profissionais que atuam PNSC e quatro (10,2\%) que operam no PNC possuem remuneração mensal acima de um salário mínimo. A diferença encontrada entre os PARNAs pode ser atribuída à obrigatoriedade da contratação de condutores de visitantes no PNSC. No caso do PNC (em que não existe a obrigatoriedade na contratação do condutor), apesar do maior número de visitantes no ano 2016 (49.617) quando comparado com o PNSC (13.902), a falta da imposição na contratação do condutor pode estar limitando a renda dos condutores e, consequentemente, o profissional que a realiza (ICMBio/SESIC, 2017). O baixo valor de remuneração observado deve, porém, ser relativizado, pois em ambos os PARNAS, além da condução (valor descrito na pergunta), há agregação de valor ao processo de condução por meio de atividades como o traslado por veículos automotores até os pontos de início/término da atividade (ambos os PARNAS), bem como pelo oferecimento de serviços como alimentação durante pernoite (PNC). A cadeia produtiva, nestes casos, está sendo ocupada pelos mesmos atores, o que aumenta a renda final da atividade.

Se comparada ao salário médio no Estado do Piauí ( $R \$ 1.122,00)$, apresentado pela Pesquisa Nacional por Amostra de Domicílios (IBGE 2015), ou com o salário médio do estado do Espirito Santo ( $R \$ 1.074,00)$, a renda média mensal auferida pela atividade de condução está próxima dos valores encontrados para os respectivos estados. Esssa renda pode não suprir as necessidades básicas de uma família. Porém, conforme destacado por Irving (2006), é capaz de promover a inclusão social e o empoderamento das comunidades lindeiras nos PARNAs investigados.

Apesar de a maioria dos 79 condutores entrevistados nesta pesquisa ter realizado o curso de capacitação de condutor de visitantes, nove ainda não tiveram oportunidade de realizar esse curso (um do PNSC e oito do PNC). Um dado interessante da análise aparece ao considerar o nível de formação dos condutores de visitantes que diz respeito à realização de curso específico de condutor. Enquanto que este curso foi realizado por todos os 30 condutores que possuem o curso de graduação, nove $(18,4 \%)$ condutores não graduados não o realizaram. Embora o condutor do PNSC ainda não tenha realizado tal curso, obteve o curso de guarda-parques com 
chancela da Universidade Federal de Lavras (MG) no ano 2003, o que the confere o direito de conduzir, de acordo com $\S 2^{\circ}$ do artigo $11^{\circ}$ da Instrução Normativa $n^{\circ}$ 2, da ICMBio (BRASIL, 2016). Os demais condutores que não têm o curso de capacitação devem tê-lo concluído até maio de 2017 para obter a respectiva licença ou fazer a reciclagem, atendendo à referida Instrução Normativa.

No que diz respeito ao curso de formação de condutores de visitantes, este estudo entende que corresponde a uma situação de aprendizagem não-formal, pois não atende aos requisitos apontados por Nelson, Cushion e Potrac (2006), Jarvis (2012) e Trudel, Culver e Richard (2016) para ser denominada formal, nomeadamente a não organização sob a forma de um programa educacional com frequência obrigatória ou currículo padronizado que exige avaliações institucionais para atingir a certificação (a exemplo do que fazem os cursos de graduação).

\section{Necessidades formativas dos condutores de visitantes}

Com o propósito de melhor compreender as necessidades formativas dos condutores de visitantes, os resultados contidos na Tabela 2 apresentam vasto repertório de demandas relatadas pelos condutores investigados. De modo geral, os entrevistados manifestaram preferência por cursos de capacitação predominantemente práticos e que contemplem mais a realidade específica de cada PARNA investigado.

Diante das características regionais e respectivos biomas, os condutores acreditam que os cursos que poderiam proporcionar maior qualificação na atividade de conduzir visitantes em PARNAs necessitam ser elaborados e formatados para abordar duas situações de aprendizagem profissional: conhecimentos instrumentais para condução; e as características ecológicas do parque, região, bioma e ecossistema. Para a análise e discussão, optou-se por considerar somente as necessidades formativas que apresentaram mais de 10 ocorrências. 
Tabela 2: Necessidades formativas dos condutores.

Table 2: Educational needs of the instructors.

\begin{tabular}{llll}
\hline \multicolumn{1}{c}{$\begin{array}{c}\text { Situações de aprendizagem profissional dos } \\
\text { Condutores }\end{array}$} & PNC & PNSC & TOTAL \\
\hline Conhecimentos instrumentais & 39 & 12 & 51 \\
\hline Primeiros Socorros & 4 & 1 & 5 \\
Resgate e sobrevivência em áreas remotas e montanhas & 4 & 0 & 4 \\
Descenso por corda básico / escalada & 2 & 1 & 3 \\
Cartografia e navegação com GPS & 4 & 2 & 6 \\
Hospitalidade & 4 & 2 & 6 \\
Conhecer melhor as trilhas da unidade & 3 & 27 & 30 \\
Segundo idioma (inglês, francês e espanhol) & 1 & 0 & 1 \\
Culinária para camping & 2 & 0 & 2 \\
Curso de caminhada de longa duração & 0 & 1 & 1 \\
Curso de Metodologia do Ensino & 0 & 1 & 1 \\
Curso de Libras & 2 & 1 & 3 \\
Curso prático com os condutores mais experientes & 11 & 9 & 20 \\
\hline Características ecológicas do parque, região, bioma e ecossistema & & \\
\hline Flora & 8 & 4 & 12 \\
Fauna & 7 & 8 & 15 \\
Geologia & 5 & 11 & 16 \\
História (PARNA, pré-história e do homem americano) & 1 & 0 & 1 \\
Astronomia & 1 & 0 & 1 \\
Hidrologia & 0 & 4 & 4 \\
Arqueologia & 0 & 2 & 2 \\
Antropologia & 0 & 1 & 1 \\
Curso de observação de pássaros & 0 & 1 & 1 \\
Ecologia & 1 & 0 & 1 \\
Noções climáticas & & & \\
\hline
\end{tabular}

Fonte: Elaborada pelos autores. Source: Prepared by the authors.

\section{Conhecimentos Instrumentais}

\section{Primeiros socorros}

O curso de primeiros socorros tem o maior número de referências citado por todos os 39 condutores entrevistados no PNC e por 12 condutores do PNSC. Abaixo, estão alguns dos relatos dos condutores de visitantes de ambas as UC sobre a necessidade desta capacitação em primeiros socorros:

Preciso melhorar os primeiros socorros, isso não é só eu, mas acredito que todos, mas agora com esse plano de manejo entrando em vigor, pretendo me especializar em alguma coisa nova (Condutor 3 / PNC - graduado).

Cara, um curso diferente de montanha de primeiros socorros completo. Por que os primeiros socorros são usados até dentro de casa mesmo. Mas um curso bom. Não é um curso 
como eles dão aí. É um curso de primeiros socorros para montanha mesmo (Condutor 17 / PNC - não graduado).

O importante é a gente ter a capacitação mesmo de primeiros socorros, porque ao fazer uma trilha de longa distância ou pequena distância, se você não tiver um conhecimento pode acontecer algum acidente e dificulta seu trabalho. O curso de primeiros socorros não foi suficiente, pelo tempo que foi e também pelas aulas que não foram muitas, a gente fez um curso de longa duração, mas era só uma vez na semana, só no final de semana, assim eu acho que um curso de primeiros socorros é muito importante para trabalhar no parque. Acho que poderia ser um curso mais voltado só para aquilo ali mesmo que temos no parque, mais aprofundado (Condutor 49 / PNSC - não graduado).

Eu nunca precisei utilizar procedimentos de primeiros socorros como, por exemplo, acidentes com animais peçonhentos como picadas de cobra, mas eu acho que isto seria interessante. Inclusive muitas pessoas perguntam, quando a gente conduz um grupo ou uma pessoa, se levamos com a gente o soro antiofídico. Mas não temos isto. Eu acho que é algo que poderia ser trabalhado, ter uma capacitação para isto. Eu ando sempre com Fenergan por causa das picadas de insetos e das plantas urticantes que nós temos também aqui no parque. Por que tem gente que pode ter choque anafilático até com uma única picada de abelha. Então nós andamos com adrenalina e nem sei como aplicar (Condutor 61 / PNSC - graduado).

Um curso de primeiros socorros mesmo, com aprofundamento. Sinto que isto é uma deficiência e falta mais preparo e ponto de apoio, porque se acontecer alguma coisa no parque você não tem ponto de apoio, não tem estrutura e nem equipamento. Não adianta eu ser preparada e não ter como trabalhar. Tem trilhas que você faz que fica completamente sem contato, então teria que ter uma comunicação com o ICMBio e com a FUMDHAM (Condutora 68 / PNSC - graduada).

Ao levar em consideração o conteúdo mínimo desejável à capacitação de condutores apontado pelo ICMBio, consta no quadro único da Instrução Normativa $n^{\circ}$ 2/2016, de 03 de maio, o item III de segurança que envolve equipamentos e o curso de primeiros socorros (BRASIL, 2016). Em pesquisa realizada sobre o processo instrucional e as situações de risco nos esportes de aventura na natureza, Paixão (2010) identificou cinco temas considerados os mais importantes pelos 121 entrevistados, e os procedimentos de primeiros socorros aparecem em terceiro lugar com $26 \quad(21,49 \%)$ ocorrências. Cassiano et al. (2016) apontam que o curso de primeiros socorros deve ser ministrado na prática, identificando-o como primordial na formação de condutores. 
Para os autores desta investigação, o curso de primeiros socorros deve ser ministrado por profissional da área de saúde com qualificação e experiência de campo na prática. Se este requisito não for observado, o conteúdo de primeiros socorros entra na formação do condutor como coadjuvante, sem o aprofundamento necessário para aplicá-lo na prática quando necessário, como expõe o condutor 17 do PNC. De fato, a atividade de levar e trazer o visitante com segurança é imprescindível para a boa prática profissional do condutor de visitantes em PARNAs. Neste contexto, o condutor deve estar qualificado para reagir de imediato - mantendo as funções vitais do acidentado - e ser capaz de retirá-lo do interior da unidade para ser devidamente medicado em qualquer circunstância.

Os profissionais que atuam no PNSC apontaram, da mesma forma, a premência do curso de primeiros socorros, como se pode observar nas falas dos condutores 49, 61 e 68. Não ter a formação adequada para primeiros socorros a partir de cursos aprofundados, na prática, para a realidade do PARNA onde operam esteve presente na maior parte dos relatos, o que aponta a obrigação destes cursos serem ministrados por profissional apto para essa demanda, e não da maneira como vem ocorrendo. Para que isto aconteça, entende-se que a capacitação para primeiros socorros, busca e salvamento deve ser ministrado por profissional da área de saúde devidamente qualificado, em módulo separado do curso de formação de condutores, e deve ser inteiramente prático, no interior da UC, atendendo um repertório de ocorrências mais comuns de cada unidade $e$ as expectativas dos condutores. Outro aspecto que não deve passar despercebido é a formação continuada para primeiros socorros a cada dois anos, como consta na Instrução Normativa n 2/2016, de 03 de maio (BRASIL, 2016).

Além do curso de primeiros socorros, 30 condutores citaram como importante a demanda de aprender um segundo idioma, sendo 27 do PNSC. Isto era previsível, pois existe um fluxo de visitantes de outros países e pesquisadores estrangeiros que desenvolve estudos no PNSC, declarado em 1991 Patrimônio Cultural da Humanidade pela Organização das Nações Unidas pela Educação, Ciência e Cultura (Unesco).

\section{Ecologia do parque, região, bioma e ecossistemas}

A preocupação com a qualidade das informações prestadas sobre as características ecológicas do parque, da região, do bioma e do ecossistema aparece em terceiro lugar, com 20 citações referentes à flora e 12 sobre a fauna, sendo 11 para flora e oito para fauna no PNC e nove para flora e quatro para fauna no PNSC. Este aspecto chama atenção nas declarações a seguir:

Os cursos principais para começar são os de primeiros socorros, de informações sobre a vegetação lá em cima e a questão da formação rochosa. Vamos supor que você esta lá na trilha, a pessoa lhe pergunta que planta é aquela, algo sobre uma pedra, e você fica meio em dúvida e não quer responder errado, então você prefere não responder para 
não falar o que você não sabe (Condutor 2 / PNC - não graduado).

Isto deve ter surgido do início dos tempos com a revolução da natureza... acho que é por aí, pela própria natureza. Ou uma catástrofe da natureza, um negócio que pode ter acontecido, uma coisa muito forte (Condutor 21 / PNC graduado).

Dizem que foram lavas que derreteram de baixo para cima, e ondas do mar. Eu sei que a minha fé vem da palavra de Deus, aquilo que Deus fez está feito. E se Deus fez a terra assim, isso é um assunto que não me interessa (Condutor 23 / PNC - não graduado).

Cada condução é de um jeito, depende do visitante. Tem visitante que fica querendo saber tudo daqui de baixo, sobre a história do café. E tem outros, que ficam perguntando sobre plantas, que é a situação mais constrangedora do planeta quando não sei responder. Eles perguntam questões da formação rochosa das pedras. Não existe uma determinação de pontos para parar e falar sobre o local. Hoje a condução é muito do ponto de vista de cada condutor e sua experiência. Mas não existe um roteiro formatado (Condutora 38 / PNC - graduada).

No início eu acho que a vegetação é mais mata atlântica. Quando você vai subindo vira campos de altitude e vai ficando mais baixa, tem uma jaqueira se não me engano, e lá tem aquele bambu que é pequeno. Este bambu é endêmico porque eu nunca vi em outro lugar (Condutor 31 / PNC - graduado).

A vegetação eu não sei explicar, não. Eu sei que ela muda; no início da portaria é bastante mata fechada, são varias matas, tudo misturado. Aí quando você vai chegando lá em cima é tipo bambuzinho endêmico, que não pode mexer. Só ocorre aqui no Pico da Bandeira (Condutor 34 / PNC - não graduado).

Esta preocupação é mais latente nas análises dos relatos dos condutores do PNC, quando comparados com os do PNSC. Ao observar-se o relato da condutora 38 (PNC), é importante considerar o conteúdo mínimo desejável à capacitação de condutores de visitantes, que faz parte da Instrução Normativa № 2/2016, de 03 de maio, no quadro único no tema I, onde consta a importância do meio ambiente e da cultura (ênfase na UC) e a caracterização geral da unidade (BRASIL, 2016).

Nos trechos dos relatos destes condutores, é possível apontar a deficiência em não saber descrever/identificar qual vegetação que ocorre no PARNA. Além disso, foi possível identificar condutores que apresentaram confusão ao nomear mata atlântica de mata de alta montana, afora a ausência de unanimidade na definição de termos, onde aparecem, por exemplo, os termos "campos de altitude", "vegetação rupestre" e "cerrado" para descrever a mesma vegetação. Outro aspecto observado foi a ausência 
de segurança, no relato da descrição do bioma, pois afirma "achar" que a vegetação é mata atlântica e citar a jaqueira - uma espécie frutífera oriunda da Ásia, portanto exótica - como uma das árvores encontradas na área, em detrimento da diversidade de espécies da flora local, sugere uma informação equivocada.

Podem-se relacionar duas preocupações, ambas abordadas nas conclusões do estudo realizado por Pickering e Hill (2007) em áreas protegidas na Austrália, sobre a necessidade de capacitação de condutores voltada para flora de PARNAs no território brasileiro. A primeira se refere ao conhecimento, pois se o condutor não conhece a vegetação onde desenvolve seu trabalho de condução, não terá condições de conservar ou minimizar os impactos sobre esta vegetação. Em segundo lugar, para que 0 condutor de visitantes possa desempenhar atitudes de conservação durante seu trabalho em trilhas, são necessárias pesquisas de instituições de Ensino Superior nesta área, para que após as conclusões destes estudos, seja possível estruturar cursos e/ou elaborar cartilhas com conteúdos voltados para a realidade dos condutores. Esta situação também foi apontada no estudo de Cassiano et al. (2016). Desta forma, torna-se possível ao condutor conscientizar/educar os visitantes com maior propriedade, minimizando os impactos derivados do contato com a UC. Isto caracteriza a contrapartida do uso do PARNA por pesquisadores que desenvolvem estudos na unidade. No PNSC, por exemplo, existem parcerias com instituições de ensino e pesquisa neste sentido, bem como em outras UC, como no Parque Estadual da Serra do Mar em São Paulo, apontado nos estudos de Cassiano et al. (2016). Finalmente, destaca-se que os conhecimentos tradicionais dos condutores mais experientes são recursos que não podem ser menosprezados na formação destes profissionais.

A necessidade de cursos específicos de formação sobre história apareceu com 16 citações, sendo cinco para o PNC e 11 para o PNSC. Deve-se considerar que, para ambos os PARNAs, existe um rico acervo da história a ser relatado/abordado pelos condutores. No PNSC, aparecem solicitações de curso sobre a história do homem americano e da pré-história. Esta demanda se justifica pelo rico acervo de fósseis encontrados na região e pela história do homem americano contada por meio de escavações arqueológicas na UC (GUIDON; PESSIS, MARTIN, 2009; MELO, 2000; GUIDON et al., 2000; GUERIN, 1999; GUIDON et al., 1996; GUIDON; DELIBRIAS, 1986; GUIDON, 1984). Apesar de solicitado pelos condutores, após a análise dos relatos contidos nas entrevistas dos 40 condutores investigados no PNSC, considera-se que as informações prestadas sobre este assunto nos cursos oferecidos são satisfatórias, pois há a preocupação de apresentar conteúdos históricos da geologia, da fauna, das pinturas rupestres, da história do homem americano, da história da unidade, da fauna e da flora local, além da antropologia. Esta necessidade formativa pode ser atribuída à motivação da visita à UC, a qual para o PNSC é a história local.

Por outro lado, a partir da análise dos relatos dos condutores de visitantes do PNC, é possível apontar a necessidade de se organizar cursos de capacitação com profissional da área de história para socializar informações básicas sobre fatos históricos, que devem ser explorados para 
agregar mais valor às informações prestadas aos visitantes pelos condutores desta UC, de cunho procedimental e conceitual. De fato, a região tem uma rica história, que aparece em trechos das falas dos condutores a partir de menções a episódios como a guerrilha do Caparaó, os anos da ditadura militar; as quedas de aeronaves; a presença dos jesuítas; a rota de tropeiros e o atual ciclo do café.

Os relatos dos condutores investigados também revelaram outra lacuna formativa, que se refere à realização de cursos sobre as formações geológicas das UC. Das 15 citações sobre este aspecto, sete foram de condutores do PNC e oito de condutores do PNSC. No PNC, este conteúdo aparece como grave lacuna formativa, pois nenhum dos 39 condutores entrevistados soube relatar a formação geológica da unidade onde se encontra o Pico da Bandeira. Ao analisar as informações dos relatos dos condutores, é possível apontar ausência de conhecimento necessário para que os profissionais possam passar elementos corretos da formação geológica do Pico da Bandeira aos usuários. Tais conhecimentos são importantes para a boa atuação profissional dos condutores PNC, pois ao ascender o Pico da Bandeira é normal que o visitante aguce sua curiosidade para saber como ocorreu sua formação geológica e a qual cadeia de montanha pertence. Evocar uma divindade para explicar a formação geológica do PNC não parece ser a forma mais apropriada, a exemplo do que foi relatado pelo condutor 23 (PNC).

\section{Outras necessidades formativas}

Apesar de serem analisadas somente as categorias de cursos de formação com mais de 10 menções, não passaram despercebidas, nesta investigação, algumas demandas de cursos que obtiveram baixas ocorrências de resposta, mas que são importantes na formação de condutores de visitantes. Ambos os PARNAs tiveram dois pleitos de capacitação a serem ministradas especificamente por condutores locais mais experientes dentro da demanda de conhecimentos instrumentais, como se pode observar a seguir:

O primeiro é ter conhecimento da região, conhecer bem a trilha, conhecer o campo, conhecer o clima do campo que tem várias modificações, como modifica de uma hora para outra. Importante, então, é ter um curso de leitura do clima, e é importante também pegar informações com os antigos sobre como estudar o campo. O campo é um negócio minucioso, o clima daqui muda muito rápido, tem suas particularidades com a formação de nuvem e vento... o vento é uma coisa que a pessoa tem que ter conhecimento (Condutor 21 / PNC - graduado).

Eu acho que deveria ter o William, o condutor mais antigo, passando seu conhecimento para os condutores. Ele é experiente e sabe o que tem lá dentro. Ou seja, uma experiência de trabalho não é conhecimento acadêmico, é 
experiência de trabalhar lá dentro (Condutor 73 / PNSC graduado).

É pertinente expor que o condutor 73 do PNSC possui 14 anos de experiência no trabalho de condução na unidade, e o condutor 21 do PNC conduz há 32 anos. O aprendizado, durante este tempo, advém da prática ou da vivência que Schön (2008) denomina experiência de vida ou de aprendizagem na prática, e que Jarvis (2015) destaca como sendo um tempo necessário à aquisição de conhecimentos para se tornar especialista, o que não surge em um curto período de tempo. Jarvis (2015) indica que 10 anos de trabalho, ou 10.000 horas de prática, é o tempo aproximado necessário para um profissional tornar-se especialista na atividade que executa.

Nos dois exemplos anteriores, identifica-se a importância de os condutores aprenderem com os mais antigos durante suas vivências de condução em ambas as UC. É interessante ressaltar que foi observada, nos relatos dos condutores mais e menos experientes, a importância deste processo de aprendizagem na prática. $\mathrm{Na}$ investigação de Cassiano et al. (2016) observa-se a indicação do que se denomina "prática supervisionada" para atender a demanda em questão - a qual já vem ocorrendo no PNSC.

\section{O papel do condutor de visitantes em PARNAs}

Finalmente, o relato a seguir, de um profissional com 21 anos de experiência em seu ofício (condutor 43 / PNSC / não graduado), chamou a atenção por definir sinteticamente as três funções que deve exercer 0 condutor de visitantes:

Em primeiro, a preservação do patrimônio arqueológico onde funciona como um vigilante das pinturas. Hoje o parque tem a obrigatoriedade da presença do condutor nas visitas, para preservação das pinturas e para não deixar jogar lixo na trilha. Em segundo é a segurança do visitante, e em terceiro a questão das informações.

A partir deste relato e das análises realizadas neste estudo, entendese que os cursos de formação de condutores de visitantes devem ser balizados pelo tripé de funções formado pela conservação do patrimônio da UC (arqueológico e biodiversidade), pela segurança e pela qualidade das informações prestadas ao visitante. Tais funções podem ser representadas pelas categorias "conhecimentos instrumentais" e "características ecológicas do parque, região, bioma e ecossistema", encontradas no presente estudo.

Estudos em Parques Nacionais na Austrália (LUGG; SLATTERY, 2003) indicaram que o tipo de experiência é influenciado pela capacidade educacional dos guarda-parques, e que estes são frequentemente envolvidos nas demandas de natureza de ensino. No Brasil, essa prática não ocorre, haja vista que não são disponibilizados guarda-parques para 
serviços desta natureza, além de haver uma demanda reprimida por maior número de funcionários para exercerem as funções específicas inerentes à gestão dos PARNAs. Não obstante, Lugg e Slattery (2003) identificaram que a formação sobre processos ecológicos é particularmente necessária, o que pode trazer implicações positivas para o desenvolvimento profissional destes guarda-parques na gestão ambiental e no processo educacional dos visitantes, além dos objetivos e das funções que um guarda-parque deve exercer - neste caso, na Austrália. Os autores sinalizam, finalmente, que a qualificação profissional tem influência na utilização da Educação Ambiental para atividades educativas na natureza (LUGG; SLATTERY, 2003).

Segundo Lugg (2007), o Ensino Superior precisa entender seu papel para o desenvolvimento de estudos aplicados à sustentabilidade, por meio de iniciativas que possibilitem o desenvolvimento de saberes e habilidades nos discentes, os quais sejam aplicáveis em intervenções interdisciplinares no processo de ensino-aprendizagem. A autora sugere que a educação em ambientes naturais pode despertar, no ser humano, a necessidade de se preocupar com a natureza.

Independentemente da distinção das realidades entre parques australianos e brasileiros, o presente estudo defende que a formação adequada para realidade de cada PARNA é a base para proteção da biodiversidade, da cultura, da história, das pinturas rupestres, da geologia e da arqueologia, identificadas como potenciais nos dois parques onde foi desenvolvido - o que também é defendido nas investigações de Canto-Silva e Silva (2017), Cassiano et al. (2016) e Pereira, Silva e Silva-Junior (2015).

\section{Considerações finais}

É possível apontar, a partir dos relatos dos 79 condutores de visitantes investigados no PNC e no PNSC, as necessidades formativas dos profissionais que devem ser priorizadas, para que seja possível atender às demandas das unidades existentes em diversos biomas do país. Entende-se que devem ser formatados cursos de caráter predominantemente prático, que contemplem uma diversidade de conhecimentos específicos para cada UC. Os conhecimentos necessários devem ser identificados a partir do contato direto com os condutores de cada PARNA ou por meio do emprego de pesquisa-ação, pois são os condutores que identificam suas próprias necessidades formativas em seu cotidiano de conduzir visitantes.

Os resultados deste estudo permitem inferir que, independente da UC, a capacitação voltada para os primeiros socorros em áreas remotas deve ser prioridade e ministradas por profissionais da área de saúde com experiência prática. As atividades de tais cursos devem possuir caráter eminentemente prático nas trilhas dos PARNAs e apresentar características de formação continuada.

Outro aspecto que chamou atenção nos relatos dos condutores investigados em ambos os PARNAs diz respeito aos cursos de capacitação, que em sua maioria chegam como "receita de bolo", sem se ater às realidades locais, aos diferentes tipos de biomas e de terrenos e às 
características da flora, da fauna e dos condutores que atuam no PNC e PNSC. Neste sentido, se faz necessário questionar a maneira como estão sendo ministrados os cursos de capacitação de condutores, pois parecem estar transmitindo conteúdos previamente traçados em vez de compreender as necessidades formativas apontadas por cada grupo de condutores.

Os autores desta pesquisa acreditam que o principal incremento na formação continuada do condutor de visitante em UC deve ser a escolha de conteúdos que atendam às necessidades formativas deste profissional, considerando as ocorrências peculiares para cada unidade e o perfil dos condutores. Assim, acredita-se que a estruturação de cursos de formação eficazes passa por considerar as competências necessárias ao cotidiano do trabalho de conduzir, de modo que se direcione o foco da capacitação para situações-problema corriqueiras em cada PARNA, viabilizando a socialização de conteúdos que possam ser aplicados com sucesso em cada realidade local. Tais considerações sugerem capacitar o condutor de visitante, fundamentalmente, para agir na urgência e decidir na incerteza, o que deveria se constituir como diretriz principal dos cursos de formação destinados a esses profissionais.

A formação superior não parece ser imperativa na capacitação de condutores de visitantes. De fato, o convívio com outros condutores e a condução de visitantes permite ao condutor aprender ou captar informações que serão úteis ao seu processo de condução. Ou seja, este profissional é capaz de aprender em situações informais, a partir do contato com o visitante ou da observação de outro profissional. No entanto, a conclusão de um curso de graduação traz, potencialmente, mais segurança e competência ao condutor de visitantes em habilidades e conteúdos diversos, como questões didático-pedagógicas, utilização de estilos de ensino diversificado e acesso à literatura especializada que agregue informações para tornar o trabalho de condução mais eficiente e bem-sucedido.

Esta eficiência ou qualidade de conduzir visitantes tem uma relação direta com o tempo de experiência no seu trabalho, ou seja, quanto mais tempo de trabalho, possivelmente, mais qualidade terá seu ato de conduzir visitantes. Assim como ocorre nos cursos de formação de professores no Brasil, é imprescindível que os postulantes a condutores de visitantes em UC sejam submetidos a um período de estágio obrigatório durante a formação inicial, acompanhando os mais experientes durante determinado tempo para que adquiram conhecimentos práticos sobre seu ofício.

\section{Referências}

ASCOM. Publicação eletrônica [mensagem institucional da Assessoria de Comunicação do ICMBio]. Número de Parques Nacionais. Mensagem recebida por e-mail em 7 jul., 2016.

BARDIN, L. Análise de Conteúdo. Tradução de Luís A. Reto; Augusto Pinheiro. 5. ed. Lisboa: Edições 70, 2010.

BRASIL. Ministério do Meio Ambiente, Instituto Chico Mendes de Conservação da Biodiversidade. Condutores credenciados do Parque 
Nacional Serra da Capivara. Brasília, DF, Portaria no 8 de 09 de abril de 2014. Disponível em: <http://www.icmbio.gov.br/portal/images/stories/o-quefazemos/visitacao/condutores credenciados PNSC 30.05.14.pdf >. Acesso em: 31 ago. 2016.

BRASIL. Instrução normativa no 2, de 3 de maio de 2016. Dispõe sobre normas e procedimentos administrativos para autorização de uso para a prestação do serviço de condução de visitantes em unidades de conservação federais. Diário Oficial da União, Brasília, n. 84, seção 1, p. 115-116, 2016. Disponível em: < http://www.icmbio.gov.br/cepsul/images/stories/legislacao/Instrucao normati va/2016/in icmbio 22016 exerc\%C3\%ADcio atividade conducaovisitante s ucs.pdf >. Acesso em: 10 jul. 2016.

BRUHNS, H. T. No ritmo da aventura: explorando sensações e emoções. In: MARINHO, A.; BRUHNS, H. T. (Orgs.). Turismo, lazer e natureza. São Paulo: Manole, 2003.

CANTO-SILVA, C.R.; DA SILVA, J. S. Panorama da visitação e da condução de visitantes em Parques brasileiros. Revista Brasileira de Pesquisa em Turismo, v. 11, p. 365-386, 2017.

CASSIANO, A.M.; SILVA, D.S.; SEVERIAN, B.A.; LOPEZ-RICHARD, V. Desafíos para la capacitación y acreditación de guías en Unidades de Conservación: Núcleo Picinguaba del Parque Estatal Serra do Mar, Sao Paulo, Brasil. Estudios y Perspectivas en Turismo (En Línea), v. 25, p. 483-501, 2016.

COLLINS, L.; COLLINS, D. Conceptualizing the adventure-sports coach. Journal of Adventure Education and Outdoor Learning, v. 12, n. 1, p. 8193, 2012.

COTES, M.; MIELKE, M. S.; CAZORLA, I. M.; MOREL, M. Avaliação do nível de dificuldade da trilha interpretativa do Ecoparque de Una (BA): aspectos físicos, biológicos e parâmetros de esforço físico dos visitantes. Revista Brasileira Ciências do Esporte, Campinas, v. 28, n. 3, p. 191-207, 2007.

COTES, M.; MIELKE, M. S. Trilhas interpretativas em ambiente de mata atlântica: uma análise com base na estrutura da floresta. Anais do II Congresso Nacional de Planejamento e Manejo de Trilhas, 2013, Rio de Janeiro. II Congresso Nacional de Planejamento e Manejo de Trilhas / I Colóquio Brasileiro para a Red Latinoamericana de Senderismo, 16 a 18 de out., 2013.

EMPERAIRE, L. La région de la Serra da Capivara (sud-est du Piaui) et savégétation. Etudes Américanistes Interdisciplinaires. Recueil I., n. 3, p.81111, 1984.

FLICK, U. Introdução à pesquisa qualitativa. 3. ed. Porto Alegre: Artmed, 2009.

FLICK, U. Métodos qualitativos na investigação científica. Tradução de Arthur M. Pereira. Lisboa: Monitor, 2005.

GIL, A.C. Métodos e técnicas de pesquisa social. São Paulo: Atlas, 2008. 
GUERIN, C. La faune de vertébrés Du Pléistocène supérieur de l'aire archeologique de São Raimundo Nontao (Piauí, Brésil), Parigi, C.R. Acad. Sci. Paris, 312, serie II, p. 567-572, 1999.

GUIDON, N. Reflexões sobre o povoamento da América. Dédalo, São Paulo, n. 23, p. 153-162, 1984.

GUIDON, N.; DELIBRIAS, A. Carbon-14 dates point to man in the Americas 32.000 years ago. Nature, v. 321, n. 6072, p.769-71, 1986.

GUIDON, N. et al. Nature and age of the deposits in Pedra Furada, Brazil: reply to Meltzer, Adovasio e Dillehay. Antiquity, v. 70, p. 408-21, 1996.

GUIDON, N.; PEYRE, E.; GUÉRIN, C.; COPPENS, Y. Resultados da datação de dentes humanos da Toca do Garrincho, Piauí, Brasil. Anais da $X$ Reunião Científica da SAB, Clio Arqueológica, n.14, p.75-86, 2000.

GUIDON, N.; PESSIS, A.; MARTIN, G. Pesquisas Arqueológicas na região do Parque Nacional Serra da Capivara e seu entorno (Piauí-1998/2008). FUNDHAMentos, p.1- 61, 2009.

HAM, S. H. Interpretacion ambiental: una guia practica para gente con grandes ideias y presupuestos pequenos. Colorado: North American Press, 1992.

HUGO, M. L. Energy equivalent as a measure of the difficulty rating of hiking trails. Tourism Geographies, v. 1, n. 3, p. 358-373, 1999.

IBDF. Plano de Manejo para o Parque Nacional do Caparaó. Documento Técnico n. 8. Fundação Brasileira para a Conservação da Natureza, Brasília, 1981.

ICMBio. Condutores credenciados do Parque Nacional Serra da Capivara. Instituto Chico Mendes de Conservação da Biodiversidade. Portaria no 8 de 9 de abril de 2014. Disponível em: $<$ http://www.icmbio.gov.br/portal/images/stories/o-que-

fazemos/visitacao/condutores credenciados PNSC 30.05.14.pdf >. Acesso em: 10 jul. 2014.

ICMBio/SESIC. Publicação eletrônica [mensagem institucional do Sistema Eletrônico do Serviço de Informação ao Cidadão (SESIC do ICMBio]. Número de Visitantes no ano de 2016. Mensagem recebida por e-mail em 4 maio, 2017.

INGOLD, T. Perception of the Environment. Essays in Livelihood, Dwelling and Skill. New York: Routledge, 2000.

INGOLD, T. Lines: a brief history. London: Routledge, 2007.

IRVING, M.A. (Org.) Áreas protegidas e inclusão social: construindo novos significados. Rio de Janeiro: Aquarius, 2006.

IRVING, M.A. Turismo, ética e Educação Ambiental: novos paradigmas em planejamento. In: IRVING, M.A.; IRVING, J.A. (Orgs.) Turismo: o desafio da sustentabilidade. São Paulo: Ed. Futura, 2002. 
JACOBSON, S.K. El desarollo de un programa de entrenamiento para guias de ecoturismo en Tortuguero, Costa Rica. In: HAM, S.H. (Ed.) Interpretacion ambiental: una guia practica para gente con grandes ideias y presupuestos pequenos. Colorado: North American Press, 1992. p. 160162.

JARVIS, P. Learning from Everyday Life, HSSRP, v. 1, n. 1, p. 1-20, 2012.

JARVIS, P. Aprendendo a ser uma pessoa na sociedade: Aprendendo a ser Eu. In: ILLERIS, K. (Org.). Teorias Contemporâneas da Aprendizagem. Tradução de Ronaldo Cataldo Costa. Porto Alegre: Penso, p. 31-45, $2013 a$.

JARVIS, P. Aprendizagem Humana: implícita e explícita. Educação \& Realidade, Porto Alegre, v. 40, n. 3, p. 809-825, 2015.

LECHNER, L. Planejamento, implantação e manejo de trilhas em Unidades de Conservação. Tradução de Jan Gerd Shöenfelder. Cadernos de Conservação, Fundação o Boticário de Proteção à Natureza, ano 03, nº 03, Curitiba, 2006.

LUGG, A. Developing sustainability-literate citizens through outdoor learning: possibilities for outdoor education in Higher Education. Journal of Adventure Education and Outdoor Learning, v. 7, n. 2, p. 97-112, 2007.

LUGG, A; SLATTERY, D. Use of national parks for outdoor environmental education: An Australian case Study. Journal of Adventure Education and Outdoor Learning, v. 3, ed. 1, p. 77-92, 2003.

MELO, P. P. O problema do povoamento da América: uma nova proposta explicativa. Anais da X Reunião Científica da $S A B$, Clio Série Arqueologia, n. 14, p. 263-272, 2000.

MINAYO, M. C. S. (Org.). Pesquisa Social: teoria, método e criatividade. Petrópolis, RJ: Ed. Vozes, 1994.

MINISTÉRIO DO TURISMO. Portaria do Ministério do Turismo: № 27 de 30 de Janeiro de 2014 que define as atividades de condutor e guias. Disponível em: <http://www.turismo.gov.br/turismo/legislacao/portarias/20140131.html>.

Acesso em: 2 dez. 2014.

NELSON, L.J.; CUSHION, C.J.; POTRAC, P. Formal, Nonformal and Informal Coach Learning: A Holistic Conceptualisation. International Journal of Sports Science \& Coaching, v. 1, n. 3, 2006.

PAGANI, M.I., SCHIAVETTI, A., MORAES, M.E.B.D.; TOREZAN, F.H. As trilhas interpretativas da natureza e o ecoturismo. Turismo: impactos socioambientais, v. 3, p. 151-163. 1996.

PAIXÃO. J.A. O instrutor de esporte de aventura no Brasil e os saberes necessários a sua atuação profissional. Curitiba: CRV, 2012.

PAIXÃO, J.A. Training and Professional Performance of Radical Sport Instructors. International Journal of Sports Science, v. 3, n.6, p. 198-203, 2013. 
PAIXÃO, J.A. Entre a aventura e o risco: formação e atuação profissional de instrutores de esporte de aventura no estado de Minas Gerais. Revista Mackenzie de Educação Física e Esporte, v. 14, p. 257-271, 2015.

PAIXÃO, J.; TUCHER, G. Risco e aventura por entre as montanhas de Minas: a formação do profissional de esporte de aventura. Pensar a Prática, Goiânia, v. 13, n. 3, p. 1-19, set./dez., 2010.

PAIXÃO, J.A.; GABRIEL, R.E. C.D.; TUCHER, G.; KOWALSKI, M.; COSTA, V.L.M. Risco e aventura no esporte na percepção do instrutor. Psicologia \& Sociedade, v. 23, n. 2, p. 415-425, 2011.

PATTON, M. Q. Qualitative evaluation and research methods. $2^{a}$ ed. Newbury Park: Sage, 1990.

PEREIRA, A.I.A.; SILVA, F.J.L.; SILVA-JUNIOR, J.M. Influência dos cursos de capacitação do Projeto Golfinho Rotador na atuação profissional dos condutores de ecoturismo em Fernando de Noronha (PE): uma contribuição a sustentabilidade turística local. Revista Brasileira de Ecoturismo, São Paulo, v. 8, n. 1, p. 31-58, fev./abr., 2015.

PICKERING, C.M.; HILL, W. Impacts of recreation and tourism on plant biodiversity and vegetation in protected areas in Australia. Journal of Environmental Management, n. 85, p. 791-800, 2007.

RIBAS, L.C.C.; HICKENBICK, C. O Papel de Condutores Ambientais Locais e de Cursos de Capacitação no Ecodesenvolvimento Turístico e as Expectativas Sociais no Sul do Brasil. Turismo em Análise, v. 23, n. 1, p. 143-165, 2012.

SILVA, R.L. As emoções das atividades físicas de aventura na natureza e a ressignificação do papel feminino. Dissertação (Mestrado em Biociências) UFP, Rio Claro, São Paulo, 2004.

SCHÖN, D. A. Educando o profissional reflexivo: Um novo design para o ensino e a aprendizagem. Tradução de Roberto Cataldo Costa. Porto Alegre: Artmed, 2008.

SMAPR. Plano de Manejo Parque Nacional Serra da Capivara. Secretaria do Meio Ambiente da Presidência da República. Brasília - Brasil, 1994.

THOMAS, J. R.; NELSON, J. K. Método de pesquisa em atividade física. Tradução de Ricardo Petersen. 3. ed., Porto Alegre: Artemed, 2002.

TONHASCA Jr., A. Os serviços ecológicos da Mata Atlântica. Ciência Hoje, v. 35, n. 205, p. 64-67, 2004.

TONHASCA Jr., A. Ecologia e história natural da Mata Atlântica. Rio de Janeiro: Ed. Interciência, 2005.

TRUDEL, P.; CULVER, D.; RICHARD, J-P. Peter Jarvis: Lifelong learning. In: NELSON, L.; GROOM, R.; POTRAC, P. Learning in Sports Coaching: Theory and Application. Publishing Company: Routledge, 2016.

VASCONCELOS, J.M. O. Educação e Interpretação Ambiental em Unidades de Conservação. Cadernos de Conservação, Fundação o Boticário de Proteção à Natureza, ano 03, n. 04, Curitiba, 2006. 


\section{Agradecimento}

O presente trabalho contou com apoio financeiro da Coordenação de Aperfeiçoamento de Pessoal de Nível Superior (CAPES) e da Fundação de Amparo a Pesquisa do Estado da Bahia (FAPESB) na concessão da bolsa para sua realização, bem como o CNPq pela bolsa de produtividade de AS. Os pesquisadores são gratos aos condutores e gestores dos Parques Nacionais do Caparaó e Serra da Capivara e a Fundação Museu do Homem Americano (FUMDHAM).

Marcial Cotes: Universidade Estadual de Santa Cruz, Ilhéus, BA, Brasil.

E-mail: mcotes@uesc.br

Link para o currículo Lattes: http://lattes.cnpq.br/3234372265353297

William das Neves Salles: Universidade Federal de Santa Catarina, Florianópolis, SC, Brasil.

E-mail: williamdnsalles@gmail.com

Link para o currículo Lattes: http://lattes.cnpq.br/7808645575639601

Alexandre Schiavetti: Universidade Estadual de Santa Cruz, Ilhéus, BA, Brasil.

E-mail: aleschi@uesc.br

Link para o currículo Lattes: http://lattes.cnpq.br/7401911259032572

Juarez Vieira do Nascimento: Universidade Federal de Santa Catarina, Florianópolis, SC, Brasil.

E-mail: juarez.nascimento@ufsc.br

Link para o currículo Lattes: http://lattes.cnpq.br/0876604605174484

Data de submissão: 18 de agosto de 2017

Data de recebimento de correções: 24 de outubro de 2017

Data do aceite: 24 de outubro de 2017

Avaliado anonimamente 